Research Paper

\title{
Cost Utility Analysis of Cervical Therapeutic Medial Branch Blocks in Managing Chronic Neck Pain
}

\author{
Laxmaiah Manchikanti $^{1 凶}$, Vidyasagar Pampati ${ }^{1}$, Alan D. Kaye², Joshua A. Hirsch ${ }^{3}$ \\ 1. Pain Management Center of Paducah, Paducah, KY; \\ 2. LSU Health Science Center, New Orleans, LA; \\ 3. Massachusetts General Hospital and Harvard Medical School, Boston, MA. \\ $\square$ Corresponding author: Laxmaiah Manchikanti, M.D., 2831 Lone Oak Road, Paducah, Kentucky 42003 Fax: 270-554-8987 E-mail: drlm@thepainmd.com \\ (c) Ivyspring International Publisher. This is an open access article distributed under the terms of the Creative Commons Attribution (CC BY-NC) license \\ (https://creativecommons.org/licenses/by-nc/4.0/). See http://ivyspring.com/terms for full terms and conditions.
}

Received: 2017.04.26; Accepted: 2017.07.06; Published: 2017.10.15

\begin{abstract}
Background: Controlled diagnostic studies have established the prevalence of cervical facet joint pain to range from $36 \%$ to $67 \%$ based on the criterion standard of $\geq 80 \%$ pain relief. Treatment of cervical facet joint pain has been described with Level II evidence of effectiveness for therapeutic facet joint nerve blocks and radiofrequency neurotomy and with no significant evidence for intraarticular injections. However, there have not been any cost effectiveness or cost utility analysis studies performed in managing chronic neck pain with or without headaches with cervical facet joint interventions.
\end{abstract}

Study Design: Cost utility analysis based on the results of a double-blind, randomized, controlled trial of cervical therapeutic medial branch blocks in managing chronic neck pain.

Objectives: To assess cost utility of therapeutic cervical medial branch blocks in managing chronic neck pain.

Methods: A randomized trial was conducted in a specialty referral private practice interventional pain management center in the United States. This trial assessed the clinical effectiveness of therapeutic cervical medial branch blocks with or without steroids for an established diagnosis of cervical facet joint pain by means of controlled diagnostic blocks. Cost utility analysis was performed with direct payment data for the procedures for a total of 120 patients over a period of 2 years from this trial based on reimbursement rates of 2016. The payment data provided direct procedural costs without inclusion of drug treatments. An additional $40 \%$ was added to procedural costs with multiplication of a factor of 1.67 to provide estimated total costs including direct and indirect costs, based on highly regarded surgical literature. Outcome measures included significant improvement defined as at least a $50 \%$ improvement with reduction in pain and disability status with a combined $50 \%$ or more reduction in pain in Neck Disability Index (NDI) scores.

Results: The results showed direct procedural costs per one-year improvement in quality adjusted life year (QALY) of United States Dollar (USD) of \$2,552, and overall costs of USD \$4,261. Overall, each patient on average received $5.7 \pm 2.2$ procedures over a period of 2 years. Average significant improvement per procedure was $15.6 \pm 12.3$ weeks and average significant improvement in 2 years per patient was $86.0 \pm 24.6$ weeks.

Limitations: The limitations of this cost utility analysis are that data are based on a single center evaluation. Only costs of therapeutic interventional procedures and physician visits were included, with extrapolation of indirect costs.

Conclusion: The cost utility analysis of therapeutic cervical medial branch blocks in the treatment of chronic neck pain non-responsive to conservative management demonstrated clinical effectiveness and cost utility at USD $\$ 4,261$ per one year of QALY.

Key words: Chronic neck pain, cervical facet joint pain, cervical medial branch blocks, controlled diagnostic blocks, cost utility analysis, cost effectiveness analysis, quality adjusted life years (QALY). 


\section{Introduction}

Chronic neck pain in the general population with or without sprain or injury is common, with annual estimates of prevalence of $12.1 \%$ to $71.5 \%$ with most estimates demonstrating an annual prevalence of between $30 \%$ and $50 \%$ [1,2]. Though less prevalent than low back pain, neck pain is the third most common chronic pain condition in the US, is expensive, may cause persistent pain, and is the fourth leading cause of disability worldwide [3, 4]. Global burden of neck pain studies and disability studies $[3,4]$ have revealed the prevalence of chronic neck pain in $4.9 \%$ of the population, with a significant proportion suffering with chronic neck pain with high disability. Martin et al. [5, 6] evaluated health care expenditures for the treatment of back and neck problems in 2005 and demonstrated that these expenditures total approximately United States Dollar (USD) $\$ 86$ billion, with an increase of $65 \%$ between 1997 and 2005 with a $49 \%$ increase in the number of patients seeking spine-related care. In addition, Dieleman et al. [7], in an analysis of U.S. spending on personal health care from 1996 to 2013, showed that low back and neck pain accounted for the third highest amount of health care spending in the US, with an estimated USD $\$ 87.6$ billion in 2013. They also demonstrated that spending on low back and neck pain along with diabetes mellitus increased the most over the 18 years, by an estimated USD $\$ 57.2$ billion and $\$ 64.4$ billion, respectively. Multiple diagnostic and therapeutic interventions are presently offered in managing neck pain with costs being considered as uncontrollable [8-31]. Consequently, the prevalence and disability in association with escalating costs secondary to spinal pain in general and neck pain in particular have become the focus of attention of the public-at-large, payer community, regulators, and finally, physicians and patients [3, 5-7, 32].

Neck pain may originate from intervertebral discs, facet joints, ligaments, fascia, muscles, and nerve root dura [11, 12]. The current evidence shows that the prevalence of cervical facet joint pain utilizing the criterion standard of $\geq 80 \%$ pain relief to range from $36 \%$ to $67 \%$ with controlled diagnostic blocks, with a false positive rate of $27 \%$ to $63 \%$ [11, 20]. Therapeutic cervical facet joint interventions have shown Level II evidence for cervical medial branch radiofrequency neurotomy and cervical therapeutic medial branch blocks with limited evidence for intraarticular injections with best evidence synthesis $[12,20]$. Thus, there continue to be significant discussions surrounding various treatment modalities used in the management of chronic neck pain. Further, these discussions are exemplified by no demonstration of cost effectiveness or utility, increasing disability challenges, escalating utilization, diagnostic accuracy, and therapeutic effectiveness of various modalities [7, 11, 12, 20, 33-36]. Manchikanti et al. $[8-10,18]$ previously demonstrated that interventional techniques for chronic pain have increased dramatically from 2000 to 2014 with a $153 \%$ increase per 100,000 fee-for-service Medicare beneficiaries. Among these, cervical and thoracic facet joint injections increased $362.9 \%$, and cervical and thoracic radiofrequency increased $911.5 \%$ from 2000 to 2014, per 100,000 Medicare beneficiaries [8-10, 18].

Even though multiple cost utility or effectiveness analysis studies and reviews have been published over the years in managing spinal pain [33, 35, 37-53], there are very few studies assessing the cost utility of non-surgical techniques in managing neck pain [39, 40, 50-53]. Among the interventional techniques, there are none available for neck pain. However, there have been some studies providing cost utility analysis in managing low back and lower extremity pain. Among these, spinal cord stimulation was shown to be effective compared to conventional medical management at $€ 5,624$ per quality adjusted life years (QALY) [41]. Caudal epidural injections [47] were shown to be effective at a direct procedural cost of USD \$2,173 per QALY in managing disc herniation, spinal stenosis, discogenic pain, or post surgery syndrome. In addition, percutaneous adhesiolysis [48] was demonstrated to be cost effective at a direct procedural cost of USD \$2,650 QALY in recalcitrant post-surgery syndrome and spinal stenosis. Thus, the cost utility analysis does not provide the total cost. Highly regarded surgical literature from analysis of Spine Patient Outcomes Research Trial (SPORT) trial data $[45,46]$ has provided a basis for estimation of indirect cost, including drug therapy. These analyses showed overall cost effectiveness of disc herniation surgery [45] at USD $\$ 69,403$ per QALY, whereas for spinal stenosis surgeries it was USD $\$ 77,600$ per QALY and USD $\$ 115,600$ per QALY for degenerative spondylolisthesis [46]. Further, these studies also showed direct costs without medication costs to be $60 \%$ for spinal stenosis, $68 \%$ for disc herniation, and $71 \%$ for degenerative spondylolisthesis with spinal stenosis with total costs of USD \$26,222, $\$ 27,341$, and $\$ 42,081$, respectively. Based on these studies considering the direct procedural costs lowest at $60 \%$ and highest indirect costs of $40 \%$, the cost utility of caudal epidural injections is estimated to be USD $\$ 3,628$ and for percutaneous adhesiolysis, it is estimated to be USD $\$ 4,426$ per QALY with multiplication of the costs by $1.67[47,48]$. In addition, 
cost utility analysis of lumbar interlaminar epidural injections in the treatment of lumbar disc herniation, central spinal stenosis, and axial or discogenic low back pain utilizing the extrapolate method of surgical interventions of direct cost, showed an average cost of USD \$3,301 per QALY [49].

The present investigation, therefore, was undertaken to produce pragmatic, reliable, overall cost utility information for therapeutic cervical medial branch blocks in managing chronic neck pain, with or without headache and upper extremity pain, based on a previously conducted double-blind, randomized, controlled trial with a 2-year follow-up [54,55].

\section{Methods}

\section{Study Design}

The current procedural cost utility analysis is based on a randomized controlled, double-blind trial of therapeutic cervical facet joint nerve blocks [54, 55].
Design and methodology of the trial were previously described [54, 55]. All patients in the trial had previously failed conservative treatment. After receiving $80 \%$ pain relief with controlled diagnostic blocks, they underwent therapeutic injections, either with or without steroids, in a contemporary interventional pain management setting in an ambulatory surgical center in the United States.

\section{Analysis}

The 120 patients in the trial, randomized into a group that received either local anesthetic or local anesthetic with steroids, were followed for 24 months (Fig. 1).

Reimbursement rates as of 2016, for all patients from all carriers, are the basis of costs used for both facility and physician services, due to the ever-changing nature of costs $[56,57]$.

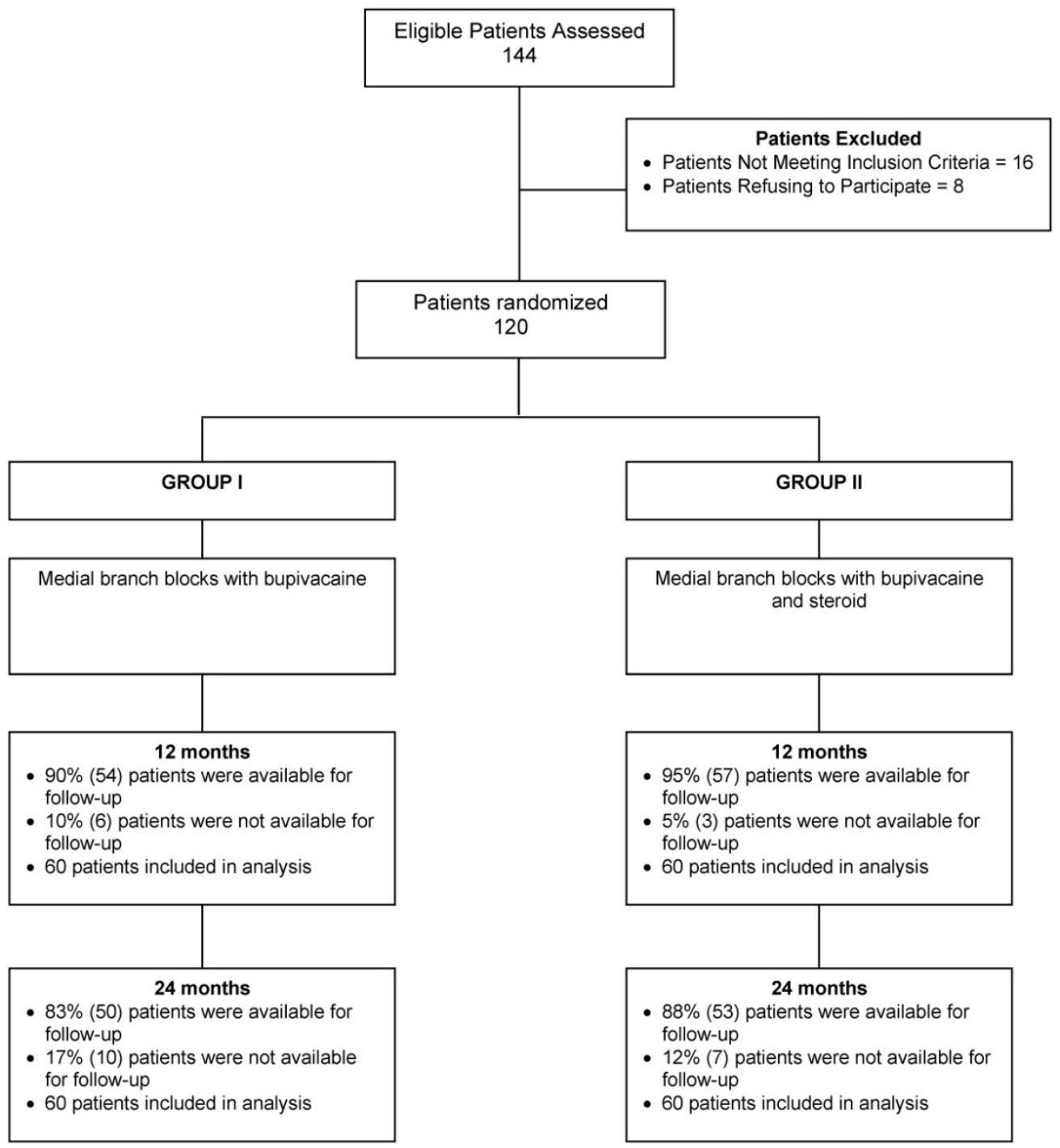

Figure 1. Schematic presentation of patient flow at 2-year follow-up for therapeutic cervical facet joint nerve blocks [54, 55]. 


\section{Outcome Measures}

Outcomes were measured at post-treatment 3, 6, 12, 18, and 24 months. Measurements included pain using the 11-point $(0$ - 10) numeric rating scale (NRS), the 0 - 50 Neck Disability Index (NDI), employment status, and opioids measured as morphine equivalents. Pain relief and disability improvement of $50 \%$ were used as improvement measures.

\section{Cost Utility Analysis}

Procedural costs for 2 years were calculated using 2016 reimbursement data for both physician and facility expenses. Quality of life improvement per year (52 weeks) for 2 years (104 weeks) was estimated based on the costs of primary outcomes of significant pain relief and improvement in function of $50 \%$ of therapeutic cervical medial branch blocks $[54,55]$. The derived procedural costs were considered as direct costs without costs of drugs, constituting $60 \%$ of the overall cost based on widely held surgical studies [45, 46] and the remaining $40 \%$ was attributed to indirect costs. These costs were estimated from direct procedural cost data with multiplication by a factor of 1.67 .

Extrapolation of the costs in this manuscript was based on the well-regarded cost utility analysis performed in surgical interventions of lumbar disc herniation, lumbar spinal stenosis, and lumbar spondylolisthesis from the SPORT trials [45, 46]. Tosteson et al. [45, 46] in detail describe their approach to calculation of direct and indirect costs, in which direct costs comprised medical and surgical costs, whereas indirect costs included productivity losses, missed days of housekeeping, and unpaid caregivers, etc. In our approach to extrapolation of these cost ratio analysis, we have also incorporated costs of medication into indirect costs. Based on this approach, with elimination of medication costs from direct costs, transferring them to indirect costs, the SPORT trials $[45,46]$ showed a 2-year cost of managing disc herniation of USD $\$ 18,645(68 \%)$, with a total cost of USD $\$ 27,341$. Similarly, for spinal stenosis and spondylolisthesis, direct costs without medication costs were estimated to be USD $\$ 15,717$ with a total cost of USD $\$ 26,222$ or USD $\$ 29,868$ with total costs of USD $\$ 42,081$ with $60 \%$ constituting for direct medical expenses without medication for spinal stenosis and $71 \%$ apportioned to direct expense without medication for spondylolisthesis. Based on these expenses, Tosteson et al $[45,46]$ estimated QALY for disc herniation of USD $\$ 69,403$ with $68 \%$ for direct medical costs without medical therapy, USD $\$ 77,600$ for spinal stenosis with direct medical costs of $60 \%$ and USD $\$ 115,600$ per QALY for degenerative spondylolisthesis with direct medical costs of $71 \%$. Consequently, in this analysis, costs were attributed as $40 \%$ to indirect expenses including medical therapy and $60 \%$ to direct costs without medical therapy, with multiplication by a factor of 1.67 .

The present investigation compared the unadjusted mean cost per patient. Incremental cost effectiveness analysis was not performed, as this was only one group. This was a comparative effectiveness trial with both groups yielding similar results.

\section{Results}

\section{Patient Flow}

The 120 study patients receiving therapeutic medial branch blocks were grouped based on whether they received bupivacaine only or bupivacaine with steroids. In Group I, 90\% were available for follow-up at 12 months; in Group II, it was 95\%. At 24 months follow-up, $83 \%$ in Group I were available for follow-up; 88\% in Group II (Fig. 1).

\section{Outcomes}

Baseline demographics and clinical characteristics are shown in Table 1. Total employed were 21 patients and total unemployed were 13 patients combined in both groups. At the end of 24 months, total unemployed was reduced to 2 (data not shown in the table).

Table 1. Demographic characteristics and clinical characteristics of cervical therapeutic facet joint nerve blocks [54, 55].

\begin{tabular}{|c|c|c|c|c|}
\hline & & $\begin{array}{l}\text { Group I } \\
\text { (bupivacaine without steroid) } \\
(N=60)\end{array}$ & $\begin{array}{l}\text { Group II } \\
\text { (bupivacaine with steroid) } \\
(\mathrm{N}=60)\end{array}$ & $\begin{array}{l}\text { Pooled } \\
(N=120)\end{array}$ \\
\hline \multirow[t]{2}{*}{ Gender } & Male & $32 \%(19)$ & $20 \%(12)$ & $26 \%(31)$ \\
\hline & Female & $68 \%(41)$ & $80 \%(48)$ & $74 \%(89)$ \\
\hline Age (years) & Mean \pm SD & $45.7 \pm 13.2$ & $42.6 \pm 14.1$ & $44.1+13.7$ \\
\hline Height (inches) & Mean \pm SD & $66.2 \pm 3.9$ & $65.5 \pm 3.7$ & $65.9+3.8$ \\
\hline Weight (lbs.) & Mean \pm SD & $177.9 \pm 53.8$ & $169.1 \pm 40.8$ & $173.5+47.8$ \\
\hline Duration of pain (months) & Mean \pm SD & $120 \pm 122.2$ & $87 \pm 104.0$ & $103+114.2$ \\
\hline \multirow[t]{3}{*}{ Mode of onset of pain } & Gradual & $57 \%(34)$ & $57 \%(34)$ & $57 \%(68)$ \\
\hline & Sudden & $11 \%(7)$ & $11 \%(7)$ & $12 \%(14)$ \\
\hline & WC/MVA & $32 \%(19)$ & $32 \%(19)$ & $31 \%(38)$ \\
\hline
\end{tabular}

$\mathrm{WC}=$ Workers compensation, $\mathrm{MVA}=$ Motor vehicle injury 
NRS and NDI data are shown in Table 2, showing baseline to 24-month improvement to be significant, but there was no significant difference with respect to the 2 groups against each other. Figure 2 reveals that $70 \%$ of all patients had a significant reduction in the NRS and NDI at 24 months.

Table 2. Pain relief and functional assessment evaluated by Neck Disability Index (NDI) characteristics with therapeutic cervical facet joint nerve blocks $[54,55]$.

\begin{tabular}{llll}
\hline Numeric Rating Score & Group I & Group II & Pooled \\
\hline Baseline & $8.2 \pm 0.8$ & $8.2 \pm 1.1$ & $8.2 \pm 1.0$ \\
6 months & $3.6 \pm 1.1$ & $3.5 \pm 0.7$ & $3.4 \pm 0.9$ \\
& $(87 \%)$ & $(95 \%)$ & $(91 \%)$ \\
12 months & $3.7 \pm 1.2$ & $3.4 \pm 0.9$ & $3.6 \pm 1.0$ \\
& $(85 \%)$ & $(91 \%)$ & $(88 \%)$ \\
24 months & $3.5 \pm 1.0$ & $3.2 \pm 1.0$ & $3.3 \pm 1.0$ \\
& $(85 \%)$ & $(93 \%)$ & $(89 \%)$ \\
Neck Disability Index & & & \\
Baseline & $25.4 \pm 5.9$ & $25.1 \pm 5.0$ & $25.3 \pm 5.5$ \\
6 months & $12.2 \pm 5.9$ & $11.6 \pm 4.2$ & $11.9 \pm 5.1$ \\
& $(78 \%)$ & $(88 \%)$ & $(83 \%)$ \\
12 months & $11.9 \pm 5.4$ & $11.7 \pm 4.5$ & $11.8 \pm 5.0$ \\
& $(85 \%)$ & $(85 \%)$ & $(85 \%)$ \\
24 months & $11.5 \pm 5.1$ & $11.0 \pm 4.7$ & $11.2 \pm 4.9$ \\
& $(85 \%)$ & $(90 \%)$ & $(87 \%)$ \\
\hline
\end{tabular}

(_ illustrates proportion with significant pain relief $(\geq 50 \%)$ from baseline

\section{Adverse Events}

Due to lack of adverse events reported among study participants in the investigation, no costs related to adverse events were incurred.

\section{Cost Utility Analysis}

In this analysis, cost for procedure, overall cost, and cost for improvement in quality of life were assessed based on the quality of life improvement as shown in Table 3. Average total cost per patient in 2 years was also assessed.

As shown in Table 3, total direct costs without medical therapy for 2 years were USD $\$ 4,222.08$. The total direct costs for one year of improvement of quality of life were USD $\$ 2,551.65$. Whereas, with extrapolation of indirect costs with the addition of $40 \%$ costs, overall costs were estimated to be USD $\$ 4,261$.

\section{Discussion}

The cost utility analysis of therapeutic cervical medial branch blocks in chronic persistent neck pain in patients who failed to respond to conservative management, with inclusion of 120 patients with a 2-year follow-up showed QALY of USD \$2,552 for direct procedural costs without inclusion of drug costs. The overall costs with direct and indirect costs were estimated to be USD $\$ 4,261$ per QALY. Both groups of patients with or without steroids with bupivacaine showed similar results. There was significant improvement from baseline in the majority of patients.

In this analysis, current reimbursement data of 2016 was utilized from all carriers for all patients, related to changes in coverage policies and reimbursement payments and inflation $[56,57]$. Due to multiple patients having undergone bilateral procedures and facet joint nerve blocks always involved at least 2 levels, average overall cost per patient was higher than in our previous cost utility studies of caudal epidural injections [47] and lumbar interlaminar epidural injections [49], but was similar or somewhat less than percutaneous adhesiolysis [48] of USD \$3,628, USD $\$ 3,301$ and USD \$4,426, respectively. The only difference between the groups was there were no diagnostic blocks performed with caudal epidural injections. Diagnostic nerve blocks for cervical facet joint nerve blocks were not included in this analysis. Similarly, in percutaneous adhesiolysis in managing post lumbar surgery syndrome and lumbar central spinal stenosis, the prior cost of epidural injections or outcomes were also not included.

\section{$\square$ Group I 回 Group II $\square$ Pooled}

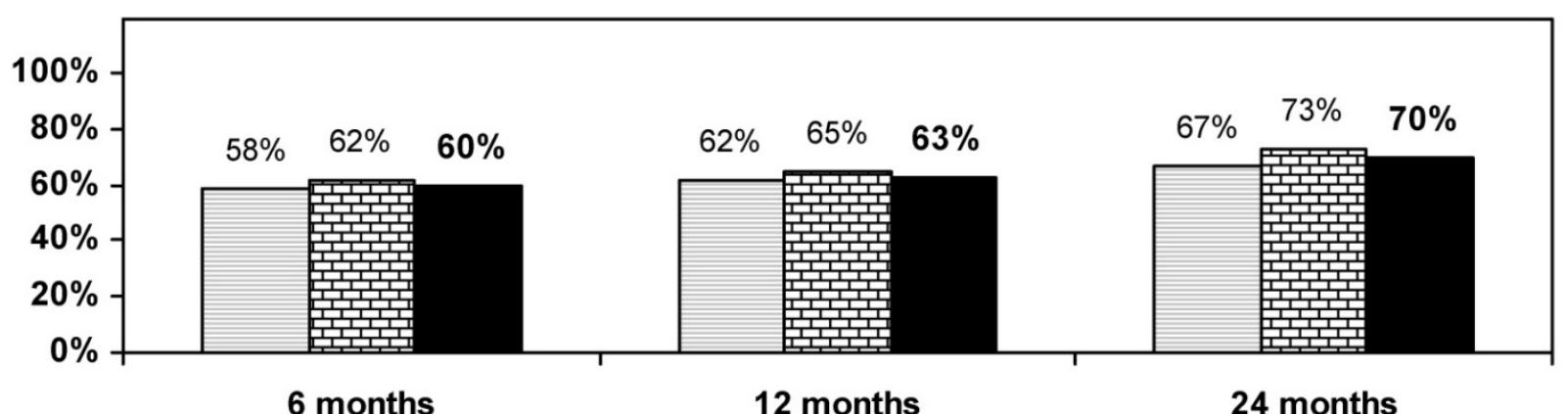

Figure 2. Proportion of patients with significant reduction in Numeric Rating Score (NRS) and Neck Disability Index (NDI) ( $\geq 50 \%$ reduction from baseline) with therapeutic cervical facet joint nerve blocks. 
Table 3. Analysis of cost effectiveness of cervical therapeutic medial branch nerve blocks in managing chronic pain (USD \$).

\begin{tabular}{|c|c|c|c|}
\hline & $\begin{array}{l}\text { Group I } \\
\text { (bupivacaine without steroid) }\end{array}$ & $\begin{array}{l}\text { Group II } \\
\text { (bupivacaine with steroid) }\end{array}$ & Pooled \\
\hline Number of patients & 60 & 60 & 120 \\
\hline Total number of procedures for 2 years & 342 & 344 & 686 \\
\hline $\begin{array}{l}\text { Number of treatments for } 2 \text { years per patient } \\
\text { (mean) } \pm \text { SD }\end{array}$ & $5.7 \pm 2.4$ & $5.7 \pm 2.1$ & $5.7 \pm 2.2$ \\
\hline $\begin{array}{l}\text { Number of weeks with significant improvement } \\
\text { for all patients in the study in weeks }\end{array}$ & 4999 & 5326 & 10325 \\
\hline $\begin{array}{l}\text { Significant improvement in two years per patient } \\
\text { (mean) } \pm \text { SD }\end{array}$ & $83.3 \pm 27.4$ & $88.8 \pm 21.1$ & $86.0 \pm 24.6$ \\
\hline $\begin{array}{l}\text { Significant improvement in weeks per procedure } \\
\text { (mean) } \pm \text { SD }\end{array}$ & $15.0 \pm 12.31$ & $16.1 \pm 14.1$ & $15.6 \pm 12.3$ \\
\hline \multicolumn{4}{|l|}{ Total Cost USD (\$) } \\
\hline Physician & $\$ 66,652.26$ & $\$ 72,340.20$ & $\$ 138,992.46$ \\
\hline Facility & $\$ 179,037.97$ & $\$ 188,619.19$ & $\$ 367,657.16$ \\
\hline Total & $\$ 245,690.23$ & $\$ 260,959.38$ & $\$ 506,649.61$ \\
\hline \multicolumn{4}{|l|}{ Cost per procedure USD (\$) } \\
\hline Physician & $\$ 194.89$ & $\$ 210.29$ & $\$ 202.61$ \\
\hline Facility & $\$ 523.50$ & $\$ 548.31$ & $\$ 535.94$ \\
\hline Total & $\$ 718.39$ & $\$ 758.60$ & $\$ 738.56$ \\
\hline Direct total costs per patient for two years USD (\$) & $\$ 4,094.84$ & $\$ 4,349.32$ & $\$ 4,222.08$ \\
\hline $\begin{array}{l}\text { Direct procedural costs without medical therapy for 1-year improvement in } \\
\text { quality of life USD (\$) }\end{array}$ & $\$ 2,555.69$ & $\$ 2,547.86$ & $\$ 2,551.65$ \\
\hline Indirect costs including drugs USD (\$) for one-year improvement of life & $\$ 1,712.31$ & $\$ 1,707.06$ & $\$ 1,709.60$ \\
\hline $\begin{array}{l}\text { Total estimated cost USD (\$) including procedural costs, drug costs, and indirect } \\
\text { costs for one-year improvement in quality of life }\end{array}$ & $\$ 4,268.00$ & $\$ 4,254.92$ & $\$ 4,261.25$ \\
\hline
\end{tabular}

The purpose of cost utility analysis in health economics is to estimate the ratio between the cost of a health-related intervention and the benefit it produces in terms of number of years lived in full health by the beneficiaries. Therefore, it can be considered as a special case of cost effectiveness analysis, and both the terms are often used interchangeably. Consequently, in this scenario, cost is measured in monetary units, unlike cost-benefit analysis, in which benefits do not have to be expressed in monetary terms. Among the studies assessing cost effectiveness of various treatments in managing chronic neck pain $[33,35,40$, 50-53], one study assessed [33] patient centered quality of life and health economics based on surgery for degenerative cervical myelopathy. A second study [35] evaluated the effect of obesity on cost per QALYs gained following anterior cervical discectomy and fusion in elective degenerative pathology. Witiw et al [33] showed mean QALY gained over the 24-month study period was 0.139 and the mean 2 years cost of treatment was Canadian (CAN) $\$ 19,217 \pm$ CAN $\$ 12,404$, with cost associated with operation comprising $65.7 \%$ of the total. They estimated lifetime incremental cost-to-utility ratios of surgical intervention of CAN $\$ 20,547$ per QALY gained. Among the studies assessing nonsurgical treatments $[40,50,51]$, Leininger et al. [50] showed that inflation adjusted costs of home exercise and advice with addition of spinal manipulative therapy would result in inflation adjusted to 2014 USD \$65,731 per QALY gained. All other assessments showed improvements in the QALY, but without cost per QALY determined.
Among earlier publications, Kepler et al [37] showed that one-year cost of QALY gained was less than USD $\$ 100,000$ in only $45 \%$ of the studies assessed. Similarly, Indrakanti et al. [38] showed that a greater value was placed on studies of non-operative treatments compared to surgical treatments. Yet, in another systematic review, Dagenais et al. [39] showed highly variable costs for QALY ranging from USD $\$ 304$ to USD $\$ 579,527$, with a median cost of USD $\$ 13,000$.

Among the interventional techniques, Taylor et al. [41] illustrated the cost effectiveness for spinal cord stimulation based on NICE criteria [58] at a cost of $£ 5,624$ per QALY. In contrast, Kumar and Rizvi [43], in an assessment of cost effectiveness of spinal cord stimulation therapy in management of chronic pain of failed back surgery syndrome, complex regional pain syndrome, peripheral arterial disease, and refractory angina pectoris, showed 2010 CAN \$9,293 CAN $\$ 11,216$, CAN \$9,350, and CAN \$9,984 for failed back surgery syndrome, complex regional pain syndrome, peripheral arterial disease, and refractory angina pectoris, respectively, per QALY gained. Overall cost utility analysis of caudal epidural injections, lumbar interlaminar epidural injections, and percutaneous adhesiolysis yielded favorable results in managing chronic low back pain of various pathologies [45-49]. Manchikanti et al. [47] performed a cost utility analysis of caudal epidural injections in the treatment of lumbar disc herniation, axial or discogenic low back pain, central spinal stenosis, and post lumbar surgery syndrome showing average direct procedure 
costs per one-year QALY of USD \$2,173 and USD $\$ 3,628$ of overall costs. Even though this study was limited to a single center, it included 480 patients in the analysis and data were derived from 4 separate randomized controlled trials (RCTs). Similarly, cost utility analysis of percutaneous adhesiolysis in managing pain of post lumbar surgery syndrome and lumbar central spinal stenosis was performed in a total of 130 patients after failure to response to caudal epidural injections from 2 RCTs from a single center showing direct procedural cost utility for one-year QALY of USD \$2,650 and overall cost of USD \$4,426 [48]. Manchikanti et al. [47] performed a cost utility analysis of lumbar interlaminar epidural injections with or without steroids in the treatment of lumbar disc herniation, central spinal stenosis, and discogenic or axial low back pain with data derived from 3 RCTs [59-61] that included a 2-year follow-up, with inclusion of 360 patients in this analysis. The methodology described in this manuscript was utilized with multiplication of procedural costs without medical therapy by a factor of 1.67 with overall cost per QALY of USD \$3,301 with direct costs of USD $\$ 1,977$, somewhat less than caudal epidural injections and significantly less than cost utility of cervical therapeutic medial branch blocks in managing chronic neck pain described in this manuscript.

Furlan et al. [40], in a systematic review and meta-analysis of efficacy, cost effectiveness, and safety of selected complementary and alternative medicine therapies for neck and low back pain, showed that alternative medicine treatments did not significantly reduce disability compared to sham, yielding mixed results. In this analysis, they included spinal manipulation in 2 studies assessing neck pain, massage in 3 studies, and acupuncture in one study. Acupuncture for neck pain was associated with significantly higher total cost compared to usual care ( $€ 1,565$ vs. $€ 1,496)$ with $€ 12,469$ per QALY gained in patients with chronic neck pain [52].

Driessen et al. [51], in another systematic review of conservative treatments for neck pain and cost effectiveness, showed that only 5 economic evaluations met inclusion criteria. In their analysis, one study [53] comparing manual therapy plus advice and exercise compared to advice and exercise showed $£ 34,000$ per QALY threshold. Leininger et al. [50] showed cost effectiveness of spinal manipulative therapy, supervised exercise, and home exercise for older adults with chronic neck pain. They showed the inflation-adjusted cost in 2014 USD \$65,731 per QALY gained, which was below the World Health Organization's recommended threshold, based on 3 times the 2014 per capita GDP of USD $\$ 163,889$.
Costs of surgical interventions are considered to be the highest in managing spinal pain $[33,35,45,46]$. Cost effectiveness analysis of posterior cervical fusion in the cervical spine showed USD \$20,547 per QALY in one study [34]; whereas, in another study [35], cost utility of anterior cervical discectomy and fusion in obese patients were USD $\$ 52,816$ per QALY.

Cost utility analysis has emerged over the years as an important tool in provision of value-based health care by merging patient-centered outcomes with utilization of health care resources [35, 59, 61, 62-64]. A cost utility analysis is a type of cost effectiveness analysis that examines the costs and effectiveness of interventions by employing the QALY as its measure of effectiveness. Essentially, cost utility analysis examines the effects of interventions on both quantity and quality of life and are considered as the standard for reporting of cost effectiveness analysis and allow policymakers and providers to compare treatment strategies among different disciplines and identify the relative priorities for optimal resource allocation among various interventions [35, 43, 65, 66]. Numerous studies have analyzed the cost effectiveness of various cervical spine interventions $[33,35,40,50,51,52,53,67,68]$. A multitude of these analyses revealed highly variable costs for conservative management, as well as surgical management of cervical disorders. Consequently, the present assessment is the first assessment ever performed for interventional techniques in managing chronic neck pain, specifically with therapeutic facet joint nerve blocks.

Indirect costs are generally not considered in health technology assessment [69-71]. In addition, based on the Affordable Care Act (ACA), cost effectiveness is not utilized as a basis for coverage or other analysis in the US [70-74]. However, cost effectiveness and cost utility analysis are frequently utilized as a basis for coverage in other countries including the United Kingdom [58]. These assessments are based on health technology assessment guidance. Despite the fact that the US does not openly consider cost utility analysis for coverage, the importance of high quality with low expense has been stressed with numerous public policy decisions including the ACA, physician quality reporting systems, value-based payment systems, merit-based incentive payment systems, and accountable interventional pain management [70-85].

Multiple advantages of this study include the data derived from an RCT of 120 patients [54, 55] making it the first and only cost utility analysis from an RCT. In addition, it has been recommended that cost effectiveness models should make use of data on absolute pain including baseline pain, routinely 
collected in trials, to inform model health-related quality of life outcomes [69]. Critchlow et al. [69] strongly recommended that absolute pain categories from 11-point NRS data are used to capture key pain outcomes. We also provided transparent data for all insurers for physician and operating room services. Further, this analysis also provides a pragmatic approach as it was performed in a practical, non-academic setting, despite utilizing strict parameters of diagnosis and therapy. Direct procedural cost utility analysis of USD \$2,552 and overall costs of USD $\$ 4,261$ per QALY is below the majority of modalities described thus far and well below the incremental cost effectiveness ratio of less than $£ 20,000$ per year QALY as recommended by NICE [58]. Consequently, the cervical medial branch blocks performed as described in this RCT meet the criteria for inclusion based on NICE criteria and cost utility analysis criteria in all countries.

The limitations of this analysis are based on the fact that only current expenses in the therapeutic phase were included. In this regard, only physician and facility costs were utilized instead of analysis in various other settings, as well as other modalities utilized in conjunction with therapeutic facet joint nerve blocks (extrapolated with multiplication of a factor 1.67 of direct procedural costs), as well as the cost of the diagnostic nerve blocks. However, the benefits of returning to work, also have not been analyzed.

Utilization of diagnostic blocks also may increase the cost for 2 procedures at a cost of USD $\$ 740$ to USD $\$ 1,550$ for each patient, but with addition of 9 to 10 weeks of significant improvement, which may reduce one procedure, thus adding less than USD \$500 per QALY. In addition, use of payments from 2016 may also be criticized; however, it is essential to use the current and realistic payment rates based on dynamic changes in payment policies. In fact, there have been significant reductions in Medicare payments and those by other carriers in 2017. Consequently, utilizing 2017 data may even further reduce the cost of the procedures performed.

Overall, the cost utility analysis of this assessment based on the reimbursement for physician and facility charges in an ambulatory surgery center in a contemporary interventional pain management setting, utilizing the current data, may not apply to all settings. Further, all the patients underwent $80 \%$ pain relief as the criterion standard for inclusion in the therapeutic phase. It may be argued that radiofrequency neurotomy may be more cost effective since it provides longer-term relief [12, 13, 20]; however, there have not been any cost estimations available for cervical radiofrequency neurotomy.
Further, with expected improvement with radiofrequency of 6 months with a single treatment, and twice the costs of procedures, costs may be similar. However, as many patients presented with bilateral pain requiring bilateral therapeutic facet joint nerve blocks incorporated into this cost utility analysis, twice the number of procedures may be required with radiofrequency neurotomy as procedures are performed only on one side, increasing the potential costs and reducing cost utility value.

These costs are only applicable for procedures performed in an ambulatory surgery setting with sterile operating room [56, 57]. Consequently, it is estimated that costs of this analysis overall may be approximately $30 \%$ to $70 \%$ higher in a hospital setting and approximately $20 \%$ to $30 \%$ lower compared to an in-office setting $[56,57]$.

\section{Conclusion}

In the present investigation, the cost utility analysis of therapeutic facet joint nerve blocks in the treatment of chronic recalcitrant neck pain with or without headache and upper extremity pain shows cost utility of direct procedural cost of USD \$2,552 per QALY and overall cost utility of USD $\$ 4,261$ per QALY.

\section{Abbreviations}

QALY: quality-adjusted life year; ACA: Affordable Care Act; USD: United States Dollar; CAN: Canadian; IRB: Institutional Review Board; NRS: numeric rating scale; NDI: Neck Disability Index; RCTs: randomized controlled trials

\section{Acknowledgments}

The authors wish to thank Tom Prigge, MA, and Laurie Swick, BS, for manuscript review; and Tonie M. Hatton and Diane E. Neihoff, transcriptionists; for their assistance in preparation of this manuscript.

\section{Disclaimer}

There was no external funding in preparation of this manuscript. The support was from the first author's practice.

\section{Competing Interests}

Dr. Manchikanti has provided limited consulting services to Semnur Pharmaceuticals, Incorporated, which is developing nonparticulate steroids. Dr. Kaye is a speaker for Depomed and Merck, Inc. Dr. Hirsch is a consultant for Medtronic. 


\section{References}

1. Manchikanti L, Singh V, Datta $S$, et al. Comprehensive review of epidemiology, scope, and impact of spinal pain. Pain Physician. 2009; 12: E35-70.

2. Côté P, Cassidy JD, Carroll L. The Saskatchewan Health and Back Pain Survey, The prevalence of neck pain and related disability in Saskatchewan adults. Spine (Phila Pa 1976). 1998; 23: 1689-98.

3. US Burden of Disease Collaborators. The state of US health, 1999-2010: Burden of diseases, injuries, and risk factors. JAMA. 2013; 310: 591-608.

4. Hoy D, March L, Woolf A, et al. The global burden of neck pain: Estimates from the global burden of disease 2010 study. Ann Rheum Dis. 2014; 73: 1309-15.

5. Martin BI, Deyo RA, Mirza SK, et al. Expenditures and health status among adults with back and neck problems. JAMA. 2008; 299: 656-64.

6. Martin BI, Turner JA, Mirza SK, et al. Trends in health care expenditures, utilization, and health status among US adults with spine problems, 1997 2006. Spine (Phila Pa 1976). 2009; 34: 2077-84.

7. Dieleman JL, Baral R, Birger M, et al. US spending on personal health care and public health, 1996-2013. JAMA. 2016; 316: 2627-46.

8. Manchikanti L, Pampati V, Falco FJE, et al. An updated assessment of utilization of interventional pain management techniques in the Medicare population: 2000 - 2013. Pain Physician. 2015; 18: E115-27.

9. Manchikanti L, Pampati V, Hirsch JA. Utilization of interventional techniques in managing chronic pain in Medicare population from 2000 to 2014: An analysis of patterns of utilization. Pain Physician. 2016; 19: E531-46.

10. Manchikanti L, Hirsch JA, Pampati V, et al. Utilization of facet joint and sacroiliac joint interventions in Medicare population from 2000 to 2014: Explosive growth continues! Curr Pain Headache Rep. 2016; 20: 58.

11. Boswell MV, Manchikanti L, Kaye AD, et al. A best-evidence systematic appraisal of the diagnostic accuracy and utility of facet (zygapophysial) joint injections in chronic spinal pain. Pain Physician. 2015; 18: E497-533.

12. Manchikanti L, Kaye AD, Boswell MV, et al. A systematic review and best evidence synthesis of the effectiveness of therapeutic facet joint interventions in managing chronic spinal pain. Pain Physician. 2015; 18: E535-82.

13. Kaye AD, Manchikanti L, Abdi S, et al. Efficacy of epidural injections in managing chronic spinal pain: A best evidence synthesis. Pain Physician. 2015; 18: E939-1004.

14. Manchikanti L, Nampiaparampil DE, Manchikanti KN, et al. Comparison of the efficacy of saline, local anesthetics, and steroids in epidural and facet joint injections for the management of spinal pain: A systematic review of randomized controlled trials. Surg Neurol Int. 2015; 6: S194-235.

15. Manchikanti L, Knezevic NN, Boswell MV, et al. Epidural injections for lumbar radiculopathy and spinal stenosis: A comparative systematic review and meta-analysis. Pain Physician. 2016; 19: E365-410.

16. Grider JS, Manchikanti L, Carayannopoulos A, et al. Effectiveness of spinal cord stimulation in chronic spinal pain: A systematic review. Pain Physician. 2016; 19: E33-54

17. Manchikanti L, Nampiaparampil DE, Candido KD, et al. Do cervical epidural injections provide long-term relief in neck and upper extremity pain? A systematic review. Pain Physician. 2015; 18: 39-60.

18. Manchikanti L, Pampati V, Hirsch JA. Retrospective cohort study of usage patterns of epidural injections for spinal pain in the US fee-for-service Medicare population from 2000 to 2014. BMJ Open. 2016; 6: e013042.

19. Bhushan A, Leigh JP. National trends in occupational injuries before and after 1992 and predictors of workers' compensation costs. Public Health Rep. 2011; 126: 625-34.

20. Manchikanti L, Hirsch JA, Kaye AD, et al. Cervical zygapophysial (facet) joint pain: Effectiveness of interventional management strategies. Postgrad Med. 2016; 128: 54-68.

21. Manchikanti L, Kaye AM, Kaye AD. Current state of opioid therapy and abuse. Curr Pain Headache Rep. 2016; 20: 34

22. Rajaee SS, Bae HW, Kanim LE, et al. Spinal fusion in the United States: Analysis of trends from 1998 to 2008. Spine (Phila Pa 1976). 2012; 37: 67-76.

23. Bae HW, Rajaee SS, Kanim LE. Nationwide trends in the surgical management of lumbar spinal stenosis. Spine (Phila Pa 1976). 2013; 38: 916-26.

24. Yoshihara H, Yoneoka D. National trends in the surgical treatment for lumbar degenerative disc disease: United States, 2000 to 2009. Spine J. 2015; 15: 265-71.

25. Rudd RA, Aleshire N, Zibbell JE, et al. Increases in drug and opioid overdose deaths - United States, 2000-2014. MMWR Morb Mortal Wkly Rep. 2016; 64: 1378-82.

26. Dowell D, Haegerich TM, Chou R. CDC Guideline for prescribing opioids for chronic pain - United States, 2016. JAMA. 2016; 315: 1624-45.

27. Manchikanti L, Kaye AM, Knezevic NN, et al. Responsible, safe, and effective prescription of opioids for chronic non-cancer pain: American Society of Interventional Pain Physicians (ASIPP) guidelines. Pain Physician. 2017; 20: S3-92.

28. Helgeson MD, Albert TJ. Surgery for failed cervical spine surgery. Spine (Phila Pa 1976). 2012; 37: E323-27.

29. Greiner-Perth R, Allam Y, El-Saghir H, et al. Analysis of reoperations after surgical treatment of degenerative cervical spine disorders: A report on 900 cases. Cen Eur Neurosurg. 2009; 70: 3-8.

30. Patil PG, Turner DA, Pietrobon R. National trends in surgical procedures for degenerative cervical spine disease: 1990-2000. Neurosurgery. 2005; 57: 753-58.
31. Boselie TF, Willems PC, van Mameren $\mathrm{H}$, et al. Arthroplasty versus fusion in single-level cervical degenerative disc disease: A Cochrane review. Spine (Phila Pa 1976). 2013; 38: E1096-107.

32. [Internet] US Social Security Administration. Annual statistical report on the Social Security Disability Insurance Program, 2011; Release July 2012. www.ssa.gov/policy/docs/statcomps/di_asr/2011/di_asr11.pdf

33. Witiw CD, Tetreault LA, Smieliauskas F, et al. Surgery for degenerative cervical myelopathy: A patient-centered quality of life and health economic evaluation. Spine J. 2017; 17: 15-25.

34. Medvedev G, Wang C, Cyriac M, et al. Complications, readmissions, and reoperations in posterior cervical fusion. Spine (Phila Pa 1976). 2016; 41: 1477-83

35. Chotai S, Sielatycki JA, Parker SL, et al. Effect of obesity on cost per quality-adjusted life years gained following anterior cervical discectomy and fusion in elective degenerative pathology. Spine J. 2016; 16: 1342-50.

36. Maciejewski ML, Arterburn DE. Cost-effectiveness of bariatric surgery. JAMA. 2013; 310: 742-3.

37. Kepler CK, Wilkinson SM, Radcliff KE, et al. Cost-utility analysis in spine care: A systematic review. Spine J. 2012; 12: 676-90.

38. Indrakanti SS, Weber $\mathrm{MH}$, Takemoto $\mathrm{SK}$, et al. Value-based care in the management of spinal disorders: A systematic review of cost-utility analysis. Clin Orthop Relat Res. 2012; 470: 1106-23.

39. Dagenais S, Caro J, Haldeman S. A systematic review of low back pain cost of illness studies in the United States and internationally. Spine J. 2008; 8: 8-20.

40. Furlan AD, Yazdi F, Tsertsvadze A, et al. A systematic review and meta-analysis of efficacy, cost-effectiveness, and safety of selected complementary and alternative medicine for neck and low-back pain. Evid Based Complement Alternat Med. 2012; 2012: 953139.

41. Taylor RS, Ryan J, O'Donnelll R, et al. The cost-effectiveness of spinal cord stimulation in the treatment of failed back surgery syndrome. Clin J Pain. 2010; 26: 463-9.

42. Gannon B, Finn DP, O'Gorman D, et al. The cost of chronic pain: An analysis of a regional pain management service in Ireland. Pain Med. 2013; 14: 1518-28.

43. Kumar K, Rizvi S. Cost-effectiveness of spinal cord stimulation therapy in management of chronic pain. Pain Med. 2013; 14: 1631-49.

44. Kumar K, Rizvi S, Bishop S, et al. Cost impact of intrathecal polyanalgesia. Pain Med. 2013; 14: 1569-84.

45. Tosteson AN, Skinner JS, Tosteson TD, et al. The cost effectiveness of surgical versus nonoperative treatment for lumbar disc herniation over two years: Evidence from the Spine Patient Outcomes Research Trial (SPORT). Spine (Phila Pa 1976). 2008; 33: 2108-15.

46. Tosteson AN, Lurie JD, Tosteson TD, et al; SPORT Investigators. Surgical treatment of spinal stenosis with and without degenerative spondylolisthesis: Cost-effectiveness after 2 years. Ann Intern Med. 2008; 149: 845-53.

47. Manchikanti L, Falco FJE, Pampati V, et al. Cost utility analysis of caudal epidural injections in the treatment of lumbar disc herniation, central spinal stenosis, post lumbar surgery syndrome, and axial or discogenic low back pain. Pain Physician. 2013; 16: E129-43.

48. Manchikanti L, Helm S 2nd, Pampati V, et al. Cost utility analysis of percutaneous adhesiolysis in managing pain of post-lumbar surgery syndrome and lumbar central spinal stenosis. Pain Pract. 2015; 15: 414-22.

49. Manchikanti L, Pampati V, Benyamin RM, Hirsch JA. Cost utility analysis of lumbar interlaminar epidural injections in the treatment of lumbar disc herniation, central spinal stenosis, and axial or discogenic low back pain. Pain Physician. 2017; 20: 219-28.

50. Leininger B, McDonough C, Evans R, et al. Cost-effectiveness of spinal manipulative therapy, supervised exercise, and home exercise for older adults with chronic neck pain. Spine J. 2016; 16: 1292-1304.

51. Driessen MT, Lin CW, van Tulder MW. Cost-effectiveness of conservative treatments for neck pain: A systematic review on economic evaluations. Eur Spine J. 2012; 21: 1441-50.

52. Willich SN, Reinhold $\mathrm{T}$, Selim $\mathrm{D}$, et al Cost-effectiveness of acupuncture treatment in patients with chronic neck pain. Pain. 2006; 125: 107-13.

53. Lewis M, James M, Stokes E, et al. An economic evaluation of three physiotherapy treatments for non-specific neck disorders alongside a randomized trial. Rheumatology (Oxford). 2007; 46: 1701-8.

54. Manchikanti L, Singh V, Falco FJ, et al. Cervical medial branch blocks for chronic cervical facet joint pain: A randomized double-blind, controlled trial with one-year follow-up. Spine (Phila Pa 1976). 2008; 33: 1813-20.

55. Manchikanti L, Singh V, Falco FJE, et al. Comparative outcomes of a 2-year follow-up of cervical medial branch blocks in management of chronic neck pain: A randomized, double-blind controlled trial. Pain Physician. 2010; 13: 437-50.

56. Manchikanti L, Singh V, Hirsch JA. Facility payments for interventional pain management procedures: Impact of proposed rules. Pain Physician. 2016; 19: E957-84.

57. Manchikanti L, Kaye AD, Hirsch JA. Proposed Medicare physician payment schedule for 2017: Impact on interventional pain management practices. Pain Physician 2016; 19: E935-55.

58. National Institute for Health and Clinical Excellence. Guide to the Methods of Technology Appraisal. London: NICE; 2008

59. Manchikanti L, Pampati V, Benyamin RM, Boswell MV. Analysis of efficacy differences between caudal and lumbar interlaminar epidural injections in chronic lumbar axial discogenic pain: Local anesthetic alone vs. local combined with steroids. Int J Med Sci. 2015; 12: 214-22. 
60. Manchikanti L, Singh V, Pampati V, et al. Comparison of the efficacy of caudal, interlaminar, and transforaminal epidural injections in managing lumbar disc herniation: Is one method superior to the other? Korean J Pain. 2015; 28: 11-21.

61. Manchikanti L, Cash KA, McManus CD, et al. A randomized, double-blind controlled trial of lumbar interlaminar epidural injections in central spinal stenosis: 2-year follow-up. Pain Physician 2015; 18: 79-92.

62. Chang RW, Pellisier JM, Hazen GB. A cost-effectiveness analysis of total hip arthroplasty for osteoarthritis of the hip. JAMA. 1996; 275: 858-65.

63. Nwachukwu BU, Schairer WW, Shifflett GD, et al. Cost-utility analyses in spine care: A qualitative and systematic review. Spine (Phila PA 1976). 2015; 40: $31-40$.

64. Rampersaud YR, Tso P, Walker KR, et al. Comparative outcomes and cost-utility following surgical treatment of focal lumbar spinal stenosis compared with osteoarthritis of the hip or knee: Part 2-estimated lifetime incremental cost-utility ratios. Spine J. 2014; 14: 244-54.

65. Pirraglia PA, Rosen AB, Hermann RC, et al. Cost-utility analysis studies of depression management: A systematic review. Am J Psychiatry. 2004; 161: 2155-62.

66. Russell LB, Gold MR, Siegel JE, et al. (Panel on Cost-Effectiveness in Health and Medicine). The role of cost-effectiveness analysis in health and medicine. JAMA. 1996; 276: 1172-7.

67. Glassman SD, Polly DW, Dimar JR, et al. The cost effectiveness of single-level instrumented posterolateral lumbar fusion at 5 years after surgery. Spine (Phila PA 1976). 2012; 37: 769-74.

68. Angevine PD, Zivin JG, McCormick PC. Cost-effectiveness of single level anterior cervical discectomy and fusion for cervical spondylosis. Spine (Phila PA 1976). 2005; 30: 1989-97.

69. Critchlow S, Hirst M, Akehurst R, et al. A systematic review of cost-effectiveness modeling of pharmaceutical therapies in neuropathic pain: Variation in practice, key challenges, and recommendations for the future. J Med Econ. 2017; 20: 129-39.

70. Public Law No: 111-148: H.R. 3590. Patient Protection and Affordable Care Act. March 23, 2010.

71. Manchikanti L, Caraway DL, Parr AT, et al. Patient Protection and Affordable Care Act of 2010: Reforming health care reform for the new decade. Pain Physician. 2011; 14: E35-67.

72. Manchikanti L, Hirsch JA. Patient Protection and Affordable Care Act of 2010: A primer for neurointerventionalists. J Neurointervent Surg. 2012; 4: 141-6.

73. Manchikanti L, Falco FJ, Benyamin RM. The impact of comparative effectiveness research on interventional pain management: Evolution from Medicare Modernization Act to Patient Protection and Affordable Care Act and the Patient-Centered Outcomes Research Institute. Pain Physician. 2011; 14: E249-82.

74. Hirsch JA, Schaefer PW, Romero JM, et al. Comparative effectiveness research. AJNR Am J Neuroradiol. 2014; 35: 1677-80.

75. Manchikanti L, Staats PS, Boswell MV, Hirsch JA. Analysis of the carrot and stick policy of repeal of the sustainable growth rate formula: The good, the bad, and the ugly. Pain Physician 2015; 18: E273-92.

76. Hirsch JA, Leslie-Mazwi TM, Barr RM, et al. The Burwell roadmap. J Neurointerv Surg. 2016; 8: 544-6.

77. Manchikanti L, Hammer M, Benyamin RM, et al. Physician Quality Reporting System (PQRS) for interventional pain management practices: Challenges and opportunities. Pain Physician. 2016; 19: E15-32.

78. Hirsch JA, Leslie-Mazwi TM, Nicola GN, et al. PORS and the MACRA: Value-based payments have moved from concept to reality. AJNR Am J Neuroradiol. 2016; 37: 2195-200.

79. Manchikanti L, Helm II S, Singh V, Hirsch JA. Accountable interventional pain management: A collaboration among practitioners, patients, payers, and government. Pain Physician. 2013; 16: E635-70.

80. Hirsch JA, Leslie-Mazwi TM, Patel AB, et al. MACRA: Background, opportunities and challenges for the neurointerventional specialist. J Neurointerv Surg. 2016; 8: 868-74.

81. Manchikanti L, Hammer MJ, Boswell MV, et al. A seamless navigation to ICD-10-CM for interventional pain physicians: Is a rude awakening avoidable? Pain Physician. 2016; 19: E1-14.

82. Manchikanti L, Helm II S, Benyamin RM, et al. Merit-Based Incentive Payment System (MIPS): Harsh choices for interventional pain management physicians. Pain Physician. 2016; 19: E917-34.

83. Manchikanti L, Helm II S, Calodney AK, et al. Merit-based incentive payment system: Meaningful changes in the final rule brings cautious optimism. Pain Physician. 2017; 20: E1-12.

84. Manchikanti L, Hirsch JA. Obamacare 2012: Prognosis unclear for interventional pain management. Pain Physician. 2012; 15: E629-40.

85. Manchikanti L, Helm S 2nd, Benyamin RM, et al. A critical analysis of ObamaCare: Affordable care or insurance for many and coverage for few? Pain Physician. 2017; 20: 111-38 